05

\title{
Закономерности десорбции воды с поверхности материалов, деформированных или дробленых в различных газовых средах
}

\author{
(c) О.В. Клявин, ${ }^{1}$ Н.Н. Аруев, ${ }^{1}$ А.О. Поздняков, ${ }^{1,2}$ Ю.М. Чернов, ${ }^{1}$ В.В. Шпейзман ${ }^{1}$ \\ ${ }^{1}$ Физико-технический институт им. А.Ф. Иофрфе РАН, \\ 194021 Санкт-Петербург, Россия \\ ${ }^{2}$ Институт проблем машиноведения РАН, \\ 199178 Санкт-Петербург, Россия \\ e-mail: shpeizm.v@mail.ioffe.ru, klyavin@mail.ioffe.ru
}

Поступило в Редакцию 1 июля 2019 г.

В окончательной редакции 1 июля 2019 г.

Принято к публикации 31 июля 2019 г.

Рассмотрено влияние среды гелия при дроблении порошка цемента и прокатке поликристаллического алюминия на количество и кинетику десорбции молекул воды с поверхности этих материалов при нагревании с постоянной скоростью. Произведено разделение пиков на кривых десорбции воды, и показано влияние среды гелия при разрушении (дроблении) и деформировании (прокатке) на характеристики десорбции. Оценены энергии активации процессов десорбции воды в различных температурных областях и их изменение при разрушении и деформации материалов в гелии и на воздухе. Высказано предположение о замещении атомами гелия вакантных для адсорбции молекул воды мест на вновь образующихся участках поверхности тел, подвергнутых механическому воздействию, и о проникновении адсорбированных атомов и молекул среды в приповерхностный слой материала по механизму дислокационно-динамической диффузии.

Ключевые слова: десорбция молекул воды, среда гелия, дробление цемента, прокатка алюминия.

DOI: 10.21883/JTF.2020.02.48816.251-19

\section{Введение}

В основе механодинамического проникновения (МДП) атомов и молекул внешней среды в кристаллические материалы лежит явление дислокационнодинамической диффузии (ДЛД) [1-6]. Оно имеет атермическую природу и получило статус научного открытия [1]. Это явление обусловлено адсорбцией частиц внешней среды на ювенильной поверхности кристаллов, образующейся в результате выхода дислокаций на поверхность или при растрескивании поверхностного слоя деформируемых материалов, и дальнейшим проникновением частиц в приповерхностный слой кристалла по зарождающимся и движущимся дислокациям. Общность явления ДДД была доказана экспериментально на поликристаллических материалах с различным размером зерна, в том числе и нанокристаллических типом решетки, при деформации в области температур $T=0.6-300 \mathrm{~K}$ на примере среды гелия и азота, находящихся в жидком или газообразном состояниях. При использовании гелия в качестве модельной среды было обнаружено [5-7], что характеристики МДП определяются наличием различных ловушек атомов гелия. В процессе его экстракции при нагревании деформированных кристаллических и аморфных материалов наблюдались отдельные пики выделения, по величине и положению на температурной шкале которых можно судить об энергетических параметрах ловушек гелия. Исследование влияния деформации на количество МДП-гелия показало, что его количество резко возрастает с ростом деформации.
Аналогичная картина наблюдалась и при использовании в качестве среды жидкого или газообразного азота, а также воды или ее паров в воздушной среде. Конкуренция различных атомов и молекул среды при их МДП может влиять на состояние дефектов в поверхностных слоях твердых тел и приводить к заметным эффектам при их деформации и разрушении. Так, исследование процесса дробления промышленного цемента в среде гелия показало [8-10], что эта среда обеспечивает получение наноразмерных частиц при резком сокращении времени и энергии его дробления по сравнению со средой воздуха. Микротвердость алюминия и железа при малых нагрузках, а также монокристаллов LiF зависит от среды (воздух, азот, гелий), в которой проводилась предварительная деформация этих материалов $[11,12]$.

В настоящей работе исследовалось влияние среды при деформации алюминия и дроблении цемента. Показано, что энергетические характеристики десорбции молекул воды зависят от типа материала, наличия пластической деформации и появления ювенильной поверхности со специфическими свойствами в процессах дробления и прокатки. Полученные данные объясняются на основе явления ДДД.

\section{1. Экспериментальные методики}

В качестве исходного сырья в настоящей работе использовался промышленный цемент марки М-400. Он диспергировался в лабораторной шаровой вибрационной мельнице типа МК-1 с агатовым шариком диа- 
метром $52 \mathrm{~mm}$. Для работы использовался стандартный технологический режим: время диспергирования $5 \mathrm{~h}$ и амплитуда колебаний шарика $A=10$ a.u. Исследовались две газовых среды - гелий и стандартная воздушная среда, которая обычно используется при дроблении промышленных материалов. Для дробления в среде гелия шаровая мельница была модернизирована с целью контролируемого впуска в ее камеру гелия и предотвращения его потерь в процессе работы мельницы. Размеры полученных частиц порошков измерялись методом динамического рассеяния света на приборе Coulter-4. На магнитном резонансном масс-спектрометре типа МИ-9301 [13] с использованием методики ионизации частиц электронным ударом с энергией $75 \mathrm{eV}$ были получены кривые выделения $\mathrm{H}_{2} \mathrm{O}$ после дробления порошка на воздухе и в гелии в области температур $T=20-700^{\circ} \mathrm{C}$ при постоянной скорости нагревания $120^{\circ} \mathrm{C} / \mathrm{min}$. Анализировался характер полученных кривых экстракции молекул $\mathrm{H}_{2} \mathrm{O}$ и их ловушек. Обработка экспериментальных кривых проводилась двумя способами. В первом - разделение пиков и оценка вклада каждого из них в общее количество десорбированной воды определялись с использованием нормального закона распределения (по Гауссу) с вычислениями по программе Origin 8.5. Во втором - путем моделирования каждой стадии процесса решением кинетического уравнения вида $d n / d t=-K n^{m}$, где $d n / d t-$ скорость десорбции молекул воды, $m-$ порядок реакции, $K-$ константа скорости вида $K=K_{0} \exp (-U / R T), K_{0}-$ предэкспоненциальный множитель, $U-$ энергия активации. Сравнение двух методов анализа кривых десорбции воды позволяло уточнить информацию о количестве воды, выделившейся на разных стадиях. Расчеты были проведены с помощью программы Fitter $^{\mathrm{TM}}$ [14], с помощью которой были получены оценки параметров кинетических уравнений для разных стадий выделения воды.

Образцы алюминия АД1 (99.3 wt.\% $\mathrm{Al})$ диаметром 3 и высотой $6 \mathrm{~mm}$ были прокатаны до толщины $0.3 \mathrm{~mm}$ при комнатной температуре в среде гелия. Кривые выделения воды из исходных и прокатанных образцов были получены при нагревании до $630^{\circ} \mathrm{C}$. Обработка результатов производилась способами, описанными выше для цемента.

\section{2. Экспериментальные результаты и их обсуждение}

\section{1. Цемент}

Зависимости скорости выделения адсорбированной воды из порошков, дробленых в гелии и на воздухе, приведены на рис. 1. Как видно, скорость десорбции воды из порошка, дробленого в гелии, гораздо меньше, чем дробленого в воздухе. Были измерены размеры частиц полученных порошков. Средний размер частиц не дробленого порошка цемента составляет $0.3-0.5 \mathrm{~mm}$,

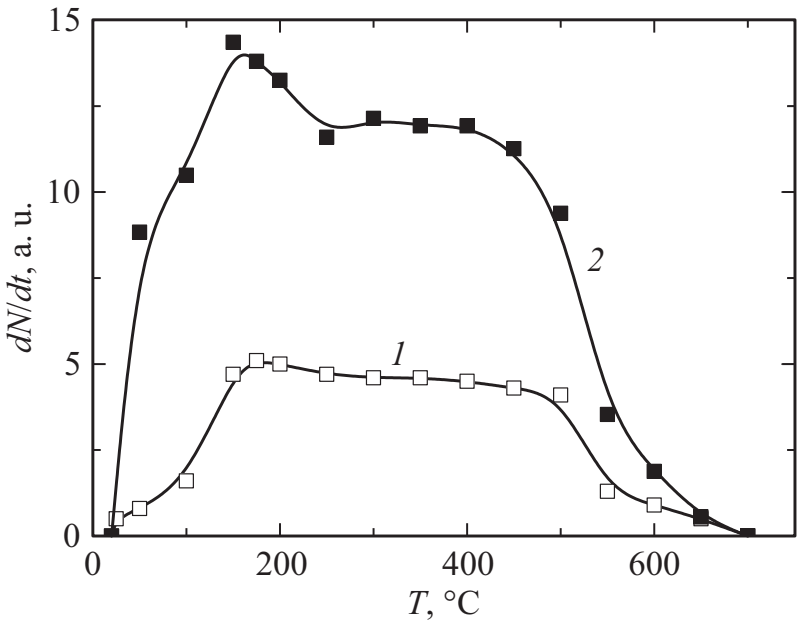

Рис. 1. Зависимость скорости выделения воды из цемента, дробленого в гелии (1) и на воздухе (2).

дробленого на воздухе $\sim 0.5 \mu \mathrm{m}$, а в гелии $\sim 10 \mathrm{~nm}$. После дробления на воздухе размеры частиц уменьшались в $10^{3}$ раз, а в гелии в $5 \cdot 10^{4}$ раз (в 50 раз больше, чем в среде воздуха). Гелий резко усиливает интенсивность процесса дробления порошка цемента. Это происходит благодаря динамической диффузии атомов гелия в частицы порошка по механизму ДДД. Температурные зависимости скорости выделения воды из порошков, дробленых на воздухе и в гелии, приведены на рис. 2 и в табл. 1. Разделение пиков по Гауссу $(\mathrm{G})$ и с использованием кинетического уравнения реакции по программе $\mathrm{Fitter}^{\mathrm{TM}}$ (F) дало близкие результаты и позволило выделить для каждого состояния материала по два пика на температурной зависимости скорости десорбции воды из порошка цемента (рис. 2). Для порошка, дробленого в среде воздуха, первый максимум появляется при $T=150(\mathrm{G})$ и $155^{\circ} \mathrm{C}(\mathrm{F})$, а для дробленого в гелии соответственно при $T=187$ и $200^{\circ} \mathrm{C}$, т.е. температура первого максимума выделения воды выше для порошка, дробленого в гелии, на $25-30 \%$. Температура второго максимума практически не зависит от среды дробления: $T=405(\mathrm{G})$ и $432^{\circ} \mathrm{C}(\mathrm{F})$ для среды гелия и $T=400(\mathrm{G})$ и $428^{\circ} \mathrm{C}(\mathrm{F})$ для воздушной среды. Отличие на $7 \%$ между температурами высокотемпературного пика, определенного разными методами, связана с заметной асимметрией низкотемпературных пиков, построенных по уравнениям $d n / d t=-K n^{m}$, для которых для улучшения аппроксимации экспериментальных данных порядок реакции $m$ был увеличен от 1 (реакция первого порядка) до 1.5 для среды воздуха и 2.9 для гелия. Изменение порядка реакции может указывать на сложную, более чем двухстадийную, кинетику выхода молекул воды, которая не разрешена в условиях нашего эксперимента. По этой же причине не совпали оценки вкладов первого и второго пиков в общее количество десорбированной воды (табл. 1). Второй максимум на кривых на рис. 2 для среды воздуха и гелия характе- 

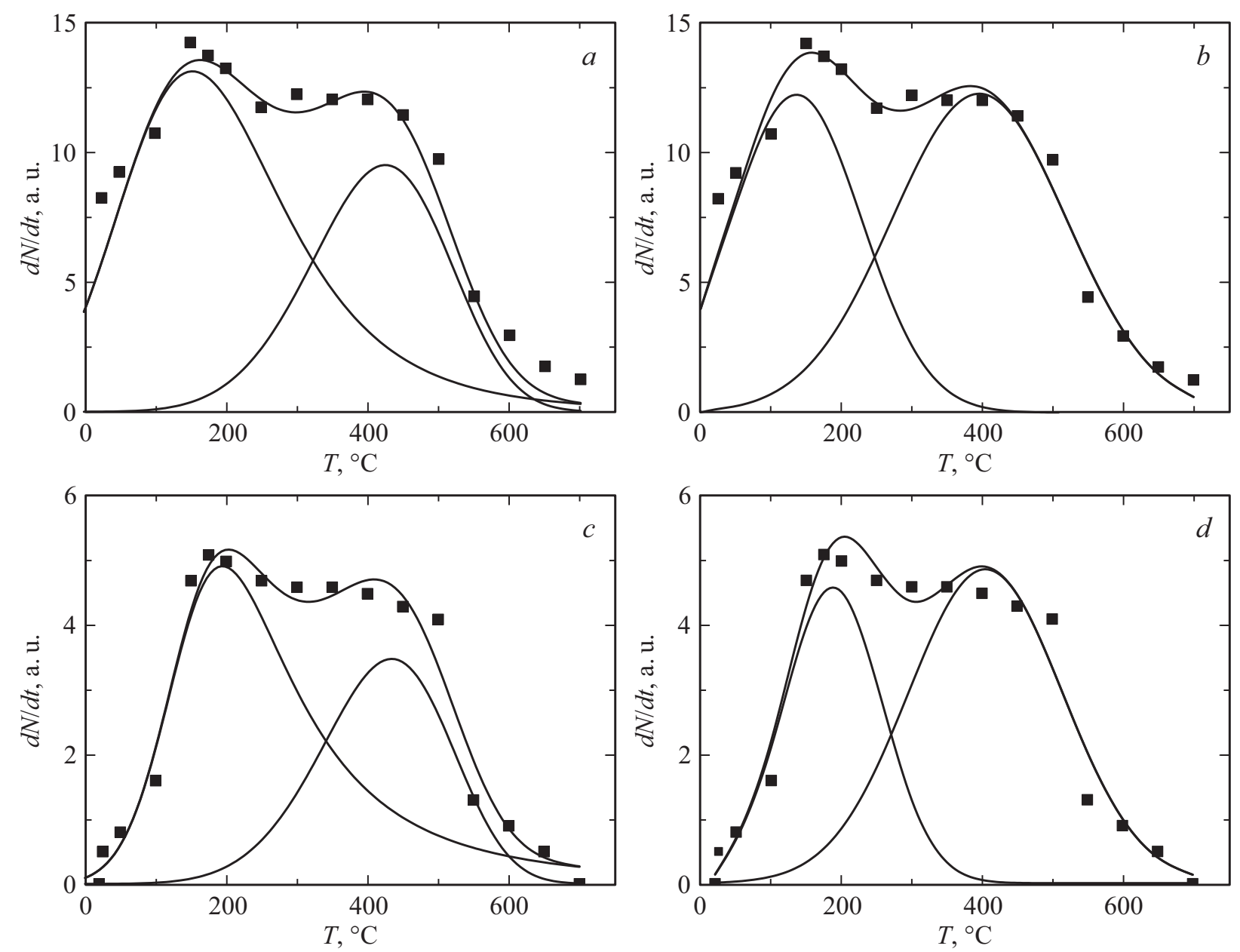

Рис. 2. Зависимость скорости выделения воды от температуры для цемента, дробленого на воздухе $(a, b)$ и в гелии $(c, d)$. Обработка данных $(a, c)$ по формулам для химических реакций и $(b, d)$ с использованием нормального закону распределения (по Гауссу).

Таблица 1. Характеристики пиков выделения воды для цемента, дробленого в гелии и на воздухе

\begin{tabular}{c|c|c|c|c|c|c|c|c}
\hline \multirow{2}{*}{ Дробление } & \multicolumn{2}{|c|}{$T_{1},{ }^{\circ} \mathrm{C}$} & \multicolumn{3}{c|}{$T_{2},{ }^{\circ} \mathrm{C}$} & \multicolumn{2}{c}{ Доля 1 пика } & \multicolumn{2}{c}{ Доля 2 пика } \\
\cline { 2 - 14 } & $\mathrm{G}$ & $\mathrm{F}$ & $\mathrm{G}$ & $\mathrm{F}$ & $\mathrm{G}$ & $\mathrm{F}$ & $\mathrm{G}$ & $\mathrm{F}$ \\
\hline $\mathrm{B} \mathrm{He}$ & 187 & 200 & 405 & 432 & 38 & 63 & 62 & 37 \\
\hline$E, \mathrm{~kJ} / \mathrm{mol} .(\mathrm{eV})$ & & $28(0.29)$ & & $40(0.41)$ & & & & \\
\hline На воздухе & 150 & 155 & 400 & 428 & 41 & 63 & 59 & 37 \\
\hline$E, \mathrm{~kJ} / \mathrm{mol} .(\mathrm{eV})$ & & $12(0.12)$ & & $36(0.37)$ & & & &
\end{tabular}

Примечание. Разделение пиков по Гауссу $(\mathrm{G})$ и с использованием кинетического уравнения реакции по программе Fitter ${ }^{\mathrm{TM}}$ (F).

ризует энергию десорбции молекул воды, содержащихся в исходном сырье и выделяющихся при его дроблении в этих средах. Поэтому он сдвинут в сторону более высоких температур и практически совпадает по энергии активации (Е) для обеих сред: при дроблении на воздухе $E=0.37 \mathrm{eV}$, в гелии $E=0.4 \mathrm{eV}$. Атомы гелия ввиду их очень малых размеров и химической инертности интенсивно проникают в движущиеся дефекты и возникающие в процессе дробления микротрещины. Это приводит к их остановке, закреплению и, как следствие, к росту локальных напряжений и интенсивному охрупчиванию частиц порошка, резкому уменьшению их размеров, времени дробления и снижению затрат энергии на получения частиц заданного размера.

Были выполнены масс-спектрометрические измерения общего содержания молекул воды в дробленых порошках. Оно оказалось почти в три раза больше для порошков, дробленых на воздухе, чем для дробленых 


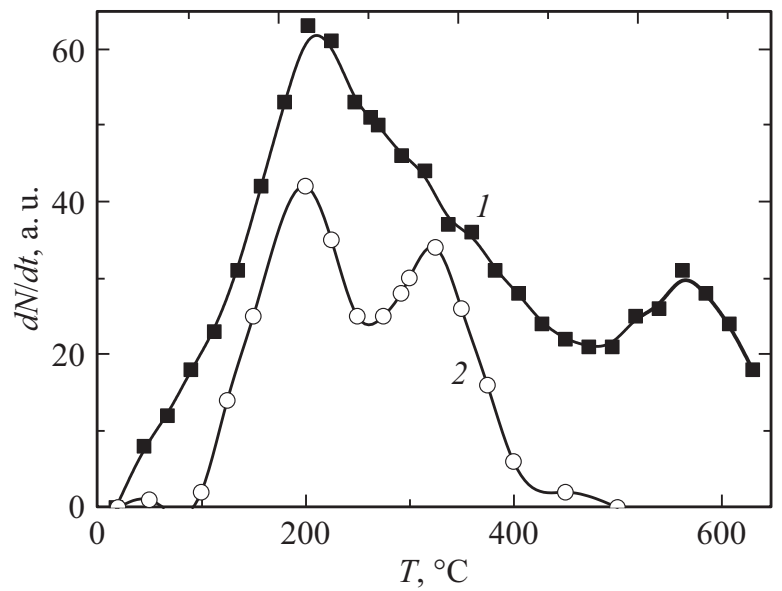

Рис. 3. Зависимость скорости выделения воды от температуры для поликристаллического алюминия: 1 - недеформированный, 2 - после интенсивной деформации.

в гелии, так как молекулы воды как компоненты воздуха входят в частицы порошка при его дроблении по механизму ДДД. Динамическая диффузия молекул воды была впервые обнаружена в [15] для монокристал- лов LiF, деформированных в обычной и тяжелой воде на разные степени деформации сжатием. Обнаружена различная концентрация молекул воды в краевых и винтовых дислокациях и глубина их проникновения по дислокациям в поверхностный слой кристаллов. Из наночастиц, полученных в среде гелия, выделяются при нагревании в основном молекулы воды, имевшиеся в исходном сырье порошка цемента, количество которых значительно превышает содержание паров воды в среде гелия. Выходу молекул воды препятствуют адсорбированные на ювенильной поверхности частиц цемента атомы гелия. Нанопорошки цемента имеют высокую насыщенность атомами гелия, возникшую в процессе их дробления. На их поверхности образуется связанный с дефектной структурой наночастиц слой атомов гелия, затрудняющий адсорбцию молекул воды. Это приводит к увеличению энергии активации десорбции воды при дроблении в гелии более чем в два раза $(E=0.28 \mathrm{eV})$ по сравнению со средой воздуха $(E=0.12 \mathrm{eV})$ и значительно уменьшает количество десорбированной воды.

Следует отметить, что при анализе энергий активации выделения гелия из порошков цемента, дробленых в гелии и на воздухе [9], наблюдается обратная картина: для частиц цемента, дробленых в гелии, эта энергия
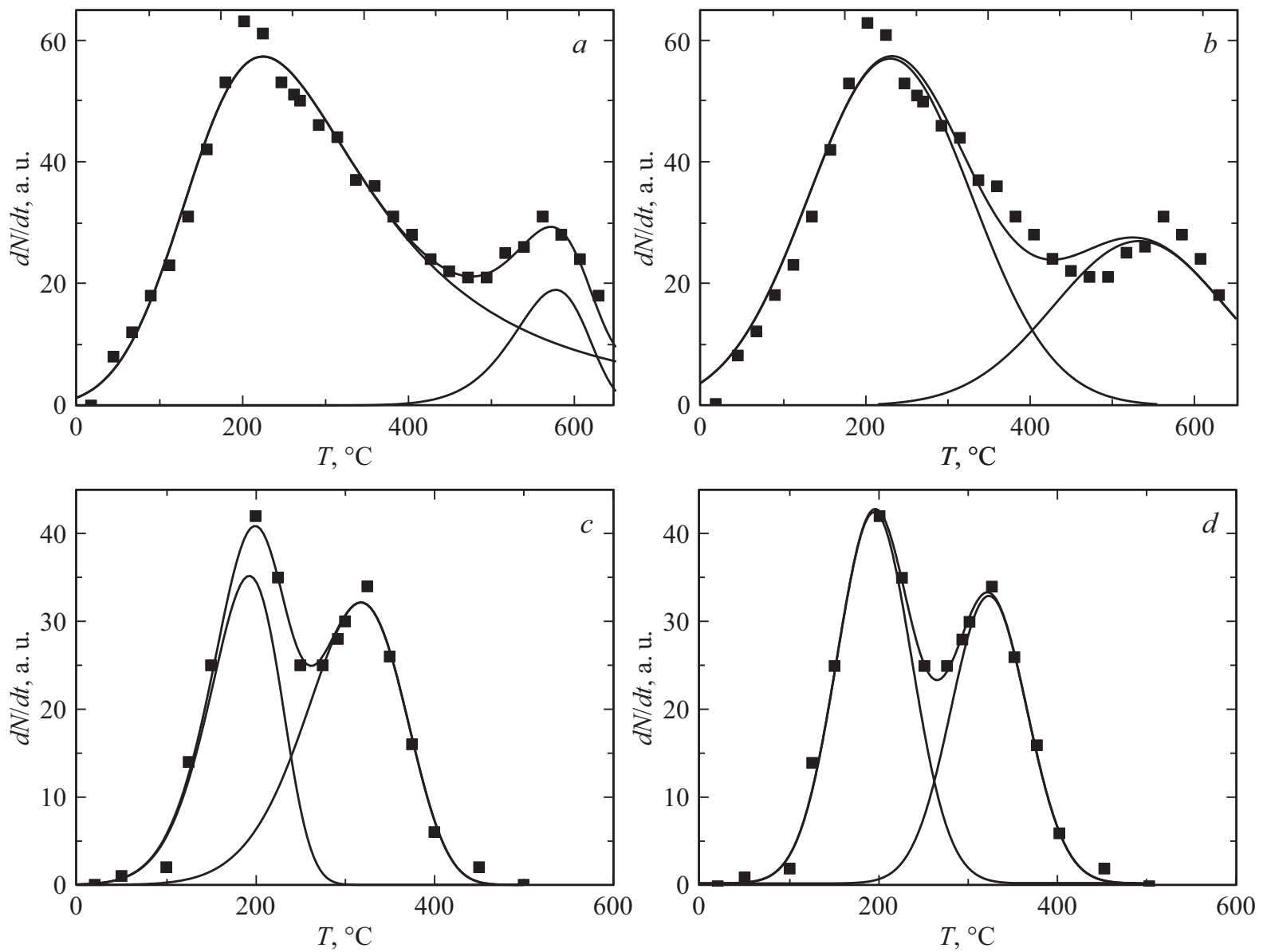

Рис. 4. Зависимость скорости выделения воды от температуры для недеформированного $\mathrm{Al}(a, b)$ и после прокатки в атмосфере гелия $(c, d)$. Обработка данных $(a, c)$ по формулам для химических реакций и $(b, d)$ с использованием нормального закону распределения (по Гауссу). 
Таблица 2. Характеристики пиков выделения воды из недеформированного и прокатанного в гелии алюминия

\begin{tabular}{|c|c|c|c|c|c|c|c|c|}
\hline \multirow{5}{*}{$\varepsilon=0$} & \multicolumn{4}{|c|}{$T_{1},{ }^{\circ} \mathrm{C}$} & \multicolumn{4}{|c|}{$T_{2},{ }^{\circ} \mathrm{C}$} \\
\hline & \multicolumn{2}{|c|}{ G } & \multicolumn{2}{|c|}{$\mathrm{F}$} & \multicolumn{2}{|c|}{ G } & \multicolumn{2}{|c|}{$\mathrm{F}$} \\
\hline & \multicolumn{2}{|c|}{232} & \multicolumn{2}{|c|}{225} & \multicolumn{2}{|c|}{532} & \multicolumn{2}{|c|}{567} \\
\hline & \multicolumn{4}{|c|}{ Доля 1 пика } & \multicolumn{4}{|c|}{ Доля 2 пика } \\
\hline & \multicolumn{2}{|c|}{70} & \multicolumn{2}{|c|}{90} & \multicolumn{2}{|c|}{30} & \multicolumn{2}{|c|}{10} \\
\hline$E, \mathrm{~kJ} / \mathrm{mol} .(\mathrm{eV})$ & & & \multicolumn{2}{|c|}{$23(023)$} & & & \multicolumn{2}{|c|}{$134(1.36)$} \\
\hline \multirow{3}{*}{$\begin{array}{c}\text { Прокат в Не } \\
\text { от } 3 \text { до } 0.3 \mathrm{~mm}\end{array}$} & \multicolumn{2}{|c|}{$T_{2 a},{ }^{\circ} \mathrm{C}$} & \multicolumn{2}{|c|}{$T_{2 b},{ }^{\circ} \mathrm{C}$} & \multicolumn{2}{|c|}{ Доля пика 2a } & \multicolumn{2}{|c|}{ Доля пика 2b } \\
\hline & G & $\mathrm{F}$ & G & $\mathrm{F}$ & G & $\mathrm{F}$ & G & $\mathrm{F}$ \\
\hline & 194 & 194 & 320 & 317 & 54 & 44 & 46 & 56 \\
\hline$E, \mathrm{~kJ} / \mathrm{mol} .(\mathrm{eV})$ & & $41(0.42)$ & & $48(0.5)$ & & & & \\
\hline
\end{tabular}

Примечание. Разделение пиков по Гауссу $(\mathrm{G})$ и с использованием кинетического уравнения реакции по программе Fitter ${ }^{\mathrm{TM}}$ (F).

ниже, чем для дробленых на воздухе. Это представляется логичным, поскольку в случае десорбции гелия, адсорбированные молекулы воды (возможно, также и другие газы, находящиеся в воздухе) затрудняют его выход из порошков, дробленых на воздухе, по сравнению с дроблеными в гелии.

\section{2. Алюминий}

В недеформированном алюминии выделение молекул воды наблюдается до температур, близких к температуре плавления (рис. 3), и, возможно, оно будет продолжаться после плавления алюминия, поскольку при температурах, близких к температуре плавления, скорость выделения воды отлична от нуля. Деформация прокаткой в среде гелия привела к уменьшению количества выделившейся воды почти в три раза и смещению пиков выделения в сторону низких температур. Как видно из рис. 4 и табл. 2, в каждом из состояний алюминия разрешены два пика зависимости скорости выделения воды от температуры, и оба метода определения характеристик пиков дают близкие результаты.

В исходном алюминии обнаружен низкотемпературный пик с $T \sim 239^{\circ} \mathrm{C}$ и энергией $E=0.23 \mathrm{eV}$ и высокотемпературный с $T \sim 545^{\circ} \mathrm{C}$ и высокой энергией активации $E=1.36 \mathrm{eV}$. Расположение пиков скорости выделения воды из алюминия в обоих состояниях (рис. 3) позволяет предположить, что после прокатки в гелии низкотемпературный пик исчез, а второй сдвинулся в сторону низких температур и раздвоился на близкие по энергиям активации $(0.42$ и $0.50 \mathrm{eV})$ пики с температурами 194 и $318^{\circ} \mathrm{C}$. При этом средняя температура максимумов $\left(256^{\circ} \mathrm{C}\right)$ близка к температуре первого пика в недеформированном алюминии. Можно полагать, что прокатка в среде гелия удалила ловушки, которые удерживали слабосвязанную воду, и изменила структуру более сильных ловушек молекул воды на поверхности и в тонком поверхностном слое образца, так что произошло заметное разделение широкого пика на два пика с более низкой энергией связи молекул воды с решеткой металла. Влиянием деформации и среды можно объяснить уменьшение общего количества молекул воды: в результате деформации в среде гелия слабо закрепленная вода ушла, а заполнение молекулами воды новых ловушек препятствует среда гелия.

\section{Заключение}

Влияние воды на разрушение и деформацию твердых тел известно давно. К классу подобных явлений можно отнести и коррозионные процессы в металлах и сплавах [16], и знаменитые эффекты Иоффе (упрочнение кристаллов $\mathrm{NaCl}$ за счет удаления поверхностных дефектов водой) [17] и Ребиндера (разупрочнение в результате воздействия адсорбированной воды) [18], и многие другие процессы. Адсорбция воды на поверхности полупроводников и диэлектриков изучена в [19], на наноразмерных пленках оксида алюминия в [20]. В настоящей работе вода выступает не в качестве основной среды, а как конкурент среды гелия, активно проникающей в материалы, подвергнутые механическому воздействию, по механизму ДДД. Снижение количества десорбированной воды и энергии активации ее десорбции при дроблении цемента на воздухе по сравнению дроблением в гелии или после деформации алюминия в гелии по сравнению с недеформированным состоянием, полученное в работе, свидетельствует о доминирующей роли гелия в эффектах, связанных с влиянием среды на механические свойства по механизму дДд.

\section{Конфликт интересов}

Авторы заявляют, что у них нет конфликта интересов. 


\section{Список литературы}

[1] Агафонов Г.И., Клявин О.В., Мамырин Б.А., Хабарин Л.В., Чернов Ю.М., Юденич В.С. Диплом на открытие: „Явление дислокационно-динамической диффузии“, № 50, выдан 20.06.97, РАЕН, МААНО. Москва.

[2] Klyavin O.V., Likhodedov N.P., Orlov A.N. // Progr. Surf. Sci. 1990. Vol. 33. N 4. P. 259.

[3] Клявин О.В., Мамырин Б.А., Хабарин Л.В., Чернов Ю.М., Бенгус В.З., Табачникова Е.О., Шумилин С.Э. // ФТТ. 2000. Т. 42. Вып. 7. С. 1256.

[4] Клявин О.В., Мамырин Б.А., Хабарин Л.В., Чернов Ю.М. // ФТТ. 2002. Т. 44. Вып. 2. С. 291.

[5] Клявин О.В., Николаев В.И., Хабарин Л.В., Чернов Ю.М., Шиейзман В.В. // ФТТ. 2003. Т. 45. Вып. 12. С. 2187.

[6] Клявин О.В., Николаев В.И., Смирнов Б.И., Хабарин Л.В., Чернов Ю.М., Шиейзман В.В. // ФТТ. 2009. Т. 51. Вып. 3. C. 473.

[7] Клявин О.В., Николаев В.И., Поздняков О.Ф., Смирнов Б.И., Чернов Ю.М., Шиейзман В.В. // Изв. РАН. Сер. физ. 2009. Т. 73. Вып. 10. С. 1503.

[8] Клявин О.В., Дринберг А.С., Чернов Ю.М., Шиейзман В.В. // ФТТ. 2012. Т. 54. Вып. 5. С. 1019.

[9] Клявин О.В., Аруев Н.Н., Болтенков Б.С., Поздняков А.О., Чернов Ю.М., Шиейзман В.В. // ФТТ. 2014. Т. 56. Вып. 2. C. 326.

[10] Клявин О.В., Аруев Н.Н., Чернов Ю.М., Дринберг А.С., Федоров В.Ю., Шпейзман В.В. // ФТТ. 2014. Т. 56. Вып. 6. C. 1131.

[11] Клявин О.В., Аруев Н.Н., Деркаченко В.И., Федоров В.Ю., Чернов Ю.М., Шиейзман В.В. // ФТТ. 2016. Т. 58. Вып. 4. C. 692.

[12] Клявин О.В., Федоров В.Ю., Чернов Ю.М., Шиейзман В.В. // ФТТ. 2015. Т. 57. Вып. 9. С. 1755.

[13] Аруев Н.Н., Болтенков Б.С. // ЖТФ. 2012. Т. 82. Вып. 8. C. 134.

[14] Pomerantsev A.L., Rodionova O.Ye. // Chem. Intell. Lab. Syst. 2005. Vol. 79. N 1-2. P. 73.

[15] Швеи, Г.И., Клявин О.В., Банщиков Г.А. // ФТТ. 1985. Т. 27. Вып. 9. С. 2618.

[16] Гликман Л.А. Коррозионно-механическая прочность металлов. Л.: Машгиз, 1955. $174 \mathrm{c.}$

[17] Иоффе А.Ф., Кирпичева Н.В., Левитская М.А. // ЖРФХО. 1924. T. 56. C. 489.

[18] Ребиндер П.А., Щукин Е.Д. // УФН. 1971. Т. 08. № 1. С. 1.

[19] Киселев В.Ф., Крылов О.В. Адсорбционные процессы на поверхности полупроводников и диэлектриков. М.: Наука, 1978. $256 \mathrm{c}$.

[20] Сайко Д.С., Ганжса В.В., Титов С.А., Арсентьев И.Н., Костюченко А.В., Солдатенко С.А. // ЖТФ. 2009. Т. 79. Вып. 12. С. 86. 